\title{
Stereotactic radiosurgery for brain metastasis from gynecological malignancies
}

\author{
EKKEHARD KASPER ${ }^{1}$, FRANZISKA IPPEN $^{1}$, ERIC WONG $^{2}$, ERIC UHLMANN $^{2}$, \\ SCOTT FLOYD $^{3}$ and ANAND MAHADEVAN ${ }^{3}$ \\ Departments of ${ }^{1}$ Neurosurgery, ${ }^{2}$ Neuro-oncology and ${ }^{3}$ Radiation Oncology, Beth Israel \\ Deaconess Medical Center, Harvard Medical School, Boston, MA 02215, USA
}

Received April 5, 2015; Accepted April 15, 2016

DOI: $10.3892 / \mathrm{ol} .2017 .5621$

\begin{abstract}
Brain metastases are relatively uncommon in gynecological malignancies, and there is limited available data on their management. The present study reports the outcomes of patients with brain metastasis from gynecological malignancies who were treated with stereotactic radiosurgery (SRS). Patients with brain metastasis from a gynecological primary site were treated with SRS using the Cyberknife ${ }^{\mathrm{TM}}$ frameless SRS system. Primary lesions were treated with a single fraction of 16-22 Gy. A total of 3 resection cavities were treated with 8 Gy 3 times, meaning a total of $24 \mathrm{~Gy}$, and 1 recurrent lesion was re-irradiated with 5 Gy 5 times, meaning a total of 25 Gy. All patients were followed up with regular magnetic resonance imaging and clinical examinations 1 month after treatment and every 2 months thereafter. A total of 20 lesions in 8 patients were included in this study; 1 patient presented with metastatic endometrial cancer and the remaining 7 presented with metastatic ovarian cancer. The median age was 61 years (range, 48-78 years). All patients had received systemic therapy prior to developing brain metastasis. A total of 3 patients underwent surgical resection and 1 patient was administered re-irradiation for recurrence. There were 3 local failures in 2 patients. The actuarial 1-, 2- and 3-year local control rates were 91,91 and $76 \%$, respectively. The median overall survival time was 29 months. No SRS-associated toxicities or neurological mortalities were observed. In conclusion, brain metastasis from gynecological malignancies is uncommon, however, SRS is a safe and effective treatment modality for local control as a primary or adjuvant treatment in patients with this disease.
\end{abstract}

Correspondence to: Dr Anand Mahadevan, Department of Radiation Oncology, Beth Israel Deaconess Medical Center, Harvard Medical School, 330 Brookline Avenue, Boston, MA 02215, USA E-mail: amahadev@bidmc.harvard.edu

Key words: stereotactic radiosurgery, gynecological malignancy, brain metastasis

\section{Introduction}

Cervical cancer is the twelfth most common malignancy in women in the USA, with 12,340 cases annually. The cancer is the second leading cause of cancer-associated mortality in women aged 20-39 years, and 4,030 patients succumb to the disease every year (1). Cervical cancer is also the third most common cancer worldwide, with an annual incidence of 530,000 cases and 250,000 mortalities expected in 2011 (2,3). Endometrial carcinoma is the most common malignancy of the female genital tract in the United States, with an estimated incidence of 49,560 cases and 8,190 mortalities annually (1). Ovarian cancer is the fifth most common cancer in women, with an estimated 22,240 new cases annually, resulting in 14,030 mortalities, as it often presents with widespread metastasis (1). Ovarian cancer often spreads loco-regionally in the abdomen and distant metastasis are infrequently observed (4). Amongst these abdominal diseases, brain metastases from malignancies of the female genital tract have rarely been reported, with an incidence of only $0.4-1.2 \%$ in metastatic cervical cancer patients (5-7), 0.3-0.9\% in the majority of metastatic endometrial cancer cases $(4,8)$ and $<2 \%$ in metastatic ovarian cancer cases $(9,10)$. Despite decades of studies on the management of brain metastases from lung, renal and gastrointestinal cancer, melanoma and other cancers, there is hardly any available literature on brain metastases from gynecological malignancies. Furthermore, other than results from case series, there are few guidelines on how to manage these patients.

There have been significant advances in the systemic management of metastatic cervical, endometrial and ovarian cancer (11-13). This has been purported to increase recognition of unusual metastatic sites such as the brain (14-17). These advances have also led to prolonged survival in such patients, meaning that quality of life, including neurocognitive effects, is an important consideration. In consideration of these facts, the present study reports the cases of a series of patients with brain metastasis who were treated in Beth Israel Deaconess Medical Center (Harvard Medical School, Boston, MA, USA) with stereotactic radiosurgery (SRS).

\section{Patients and methods}

Patients. From a database of $>1,045$ patients with brain metastases who were treated with SRS in 

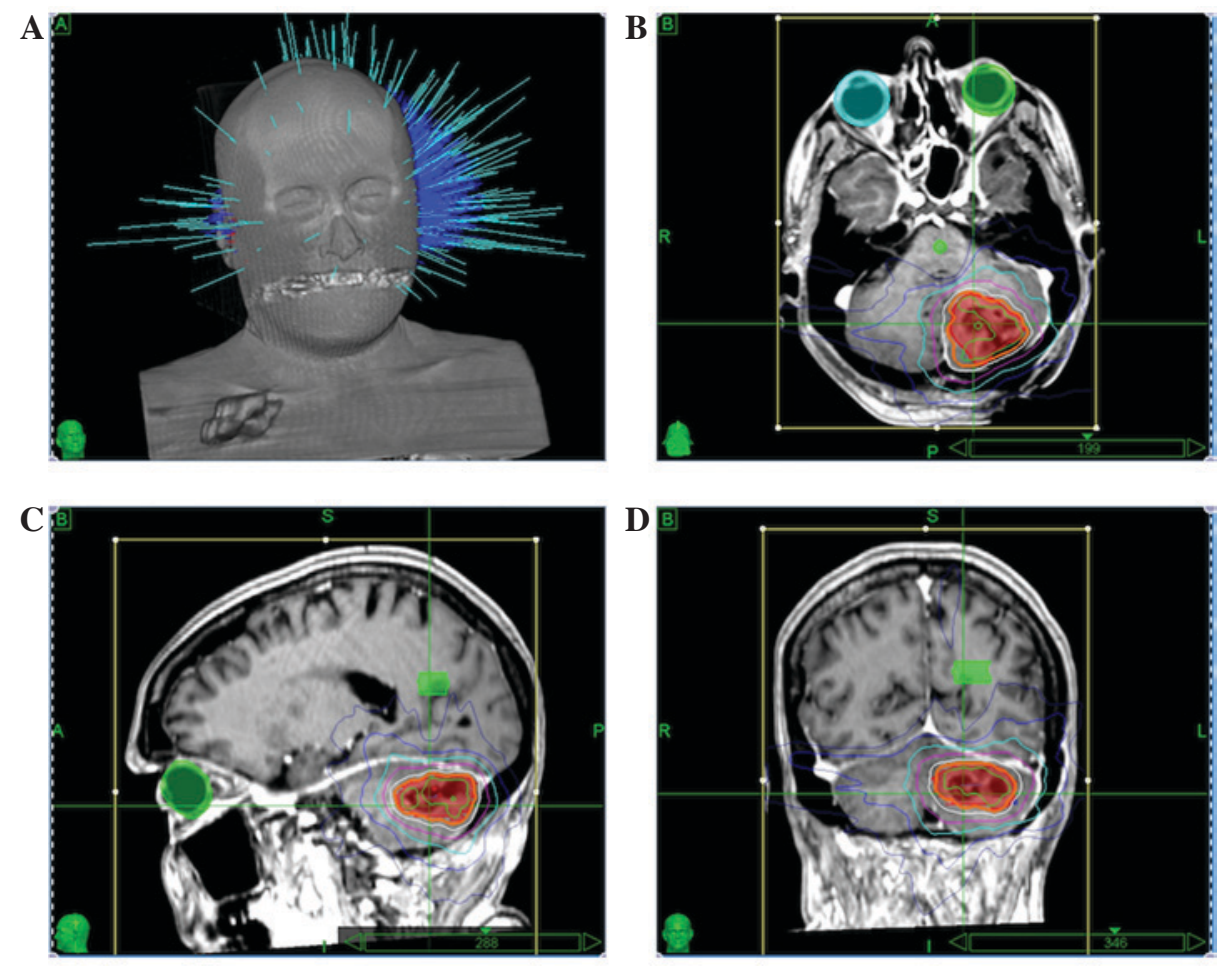

Figure 1. Representative sterotactic radiosurgery treatment of cerebellar metastasis showing (A) a non-isocentric beam profile, and (B) axial, (C) sagittal and (D) coronal magnetic resonance images, with dose distribution.

Beth Israel Deaconess Medical Center between January 2006 and February 2013, 8 patients with 20 lesions treated by SRS for brain metastasis from gynecological malignancies were identified. The medical records, including radiology and pathology records, were reviewed retrospectively for the study. The present study was approved by the Dana-Farber/Harvard Cancer Center Institutional Review Board.

Examination and treatment of patients. All patients were reviewed in the multidisciplinary brain tumor clinic and underwent diagnostic gadolinium-enhanced magnetic resonance imaging (MRI; GE Healthcare Bio-Sciences, Pittsburgh, PA, USA). The Cyberknife ${ }^{\mathrm{TM}}$ robotic SRS system (version 8.5, Accuray, Inc., Sunnyvale, CA, USA) was used to treat these patients. Prior to treatment, the patients were simulated with aquaplast (QFix, Avondale, PA, USA) mask immobilization and contrast enhanced computed tomography (CT; Toshiba American Medical Systems, Glen Mills, PA, USA) of 1-mm thickness were performed. CT MRI fusion was obtained using Multiplan ${ }^{\mathrm{TM}}$ (version 3.5; Accuray, Inc.) and the treating radiation oncologist and neurosurgeon delineated all target volumes. A representative treatment plan is shown in Fig. 1.

The enhancing tumor or resection cavity was identified as the target volume. A total 2-mm expansion for the planning target volume was awarded to resection cavities. Doses of 16, 18 or $22 \mathrm{~Gy}$ were prescribed to lesions measuring $>3,2-3$ and $<2 \mathrm{~cm}$, respectively. Lesions $>5 \mathrm{~cm}$ or resection cavities received fractions of 8 Gy 3 times, meaning a total of 24 Gy delivered on 3 consecutive days. Similarly, patients who had received prior SRS were re-irradiated with 5 Gy 5 times, meaning a total of $25 \mathrm{~Gy}$. The prescription isodose line that covered at least $95 \%$ of the target volume was chosen. All patients were pre-medicated with $4 \mathrm{mg}$ dexamethasone twice a day, starting on the day of treatment, which was tapered off after treatment by $2 \mathrm{mg}$ every 3 days, and patients with supratentorial lesions received seizure prophylaxis with leviteractam at a dose of $1,000 \mathrm{mg}$ twice a day for 1 week from the day of treatment.

Follow-up. All patients underwent neurological and radiological follow-up at 1 month post-treatment and every 2 months thereafter. Gadolinium-enhanced MRI was performed at these visits. Each patient also maintained follow-up with their medical oncologists.

\section{Results}

Between January 2006 and February 2013, 8 patients with 20 lesions were treated with SRS for single or oligo brain metastases. The mean age was 61 years (range, 41-78 years) and the median Karnofsky Performance Status score was 70. There were no metastatic cervical cancer patients in this cohort. While 1 patient presented with metastatic endometrial cancer, the remainder presented with metastatic ovarian cancer. Other potential, more common, primary sites (including co-existing lung or breast cancer) were ruled out by full staging scans. All patients had previously received systemic therapy and 1 patient had undergone whole brain radiation therapy (WBRT) 5 years earlier. While there were 11 treatment sessions for solitary lesions, 2 patients had 2 lesions each treated in 1 session and 1 patient had 5 lesions treated in 1 session. A total of 3 patients underwent a surgical 
A

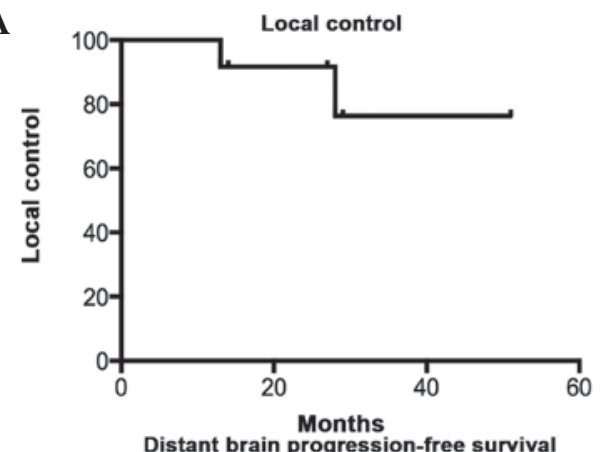

B

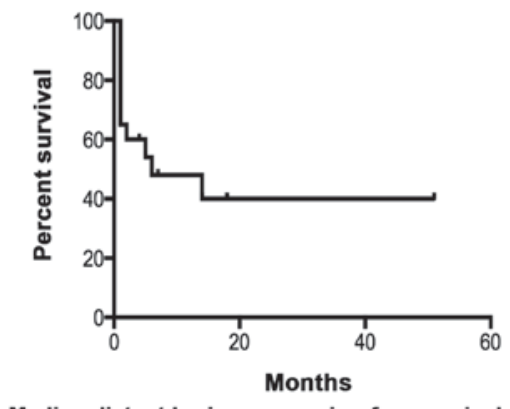

Median distant brain progression-free survival $=\mathbf{6}$ months

C

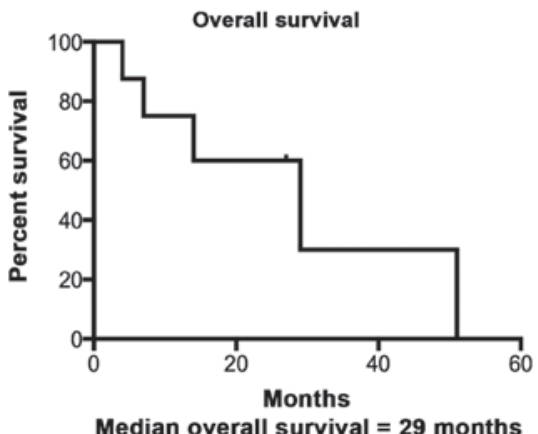

Figure 2. Kaplan Mier actuarial estimates for (A) local control, (B) distant brain progression-free survival and (C) overall survival.

resection and 1 patient was provided with re-irradiation twice. A total of 11 lesions were infratentorial, including 2 in the cerebellopontine angle.

Local recurrence occurred and was re-irradiated twice in the cerebellum of the same patient, which eventually resulted in local control at the last follow-up. There were no other local failures. A total of 6 patients otherwise demonstrated treatment failure by exhibiting metastatic disease in the rest of the brain and therefore required repeat SRS. The 1-, 2- and 3 -year actuarial local control rate was 91,76 and $76 \%$, respectively. There were 6 distant failures in 4 patients ( 2 patients demonstrated failures in the distant non-treated brain twice); salvage WBRT was administered to 1 patient for leptomeningeal failure, posterior fossa radiotherapy was administered to 1 patient and the other patients received further SRS. The median distant brain progression-free survival time was 6 months. The median overall survival time in this population was 29 months. The Kaplan-Meier survival curves for local control, distant brain progression-free survival and overall survival are shown in Fig. 2.

\section{Discussion}

Brain metastases from gynecological cancers, particularly endometrial and ovarian cancers, are extremely rare $(4,18)$, hence, there are no strong guidelines for their management $(19,20)$. Local therapy with SRS for smaller lesions and surgery for symptomatic space occupying lesions, with or without WBRT, has been the standard treatment. The management of oligometastatic brain disease in general is controversial and there is an increasing trend to use SRS in this setting. This is partially driven by worries of neurocognitive effects following WBRT (21). By contrast, in patients with widespread metastasis or leptomeningeal disease, WBRT remains the standard of care. In the present study, it was shown that patients with brain metastases from gynecological cancers, particularly ovarian cancers, can live a long time and that WBRT-sparing therapies such as SRS may be appropriate. SRS provides excellent local control and can be successfully used for salvage therapy, with limited recurrences.

With successful systemic therapy, patients with gynecological cancers may live for a long period of time (11-13). Prolonged survival rendered by effective modern systemic therapy may have led to the presumptive increase in the detection of brain metastasis (14-17) due to the inability of systemic therapy to breach the blood brain barrier (10). Randomized trials have shown no survival improvements with the addition of WBRT to surgery or radiation $(22,23)$ for brain metastasis in general. In fact, avoiding WBRT can preserve or improve neurocognitive outcomes without the expense of decreased survival (21). While long-term neurocognitive sequelae remain a concern in all patients with limited brain metastasis, it becomes particularly relevant in this group of patients who survive longer. The median overall survival time of 29 months in the present study validates this hypothesis. Other groups have reported similar overall survival times in such patients. Kastritis et al (10) reported long-term survivors, and Anupol et al (24) reported a mean survival time of 22 months in patients with brain metastasis from ovarian cancer. Similarly other studies have reported excellent local control and survival following SRS for endometrial cancer $(25,26)$. By contrast, patients with brain metastasis from cervical cancer appear to do relatively poorly $(6,27-29)$. This could reflect the inherent poor biological behavior of squamous cervical cancer.

Tumor markers are often unreliable in screening for brain metastasis (30), but cancer antigen 125 elevation can occasionally precede the clinical detection of brain metastasis (24), and elevated marker levels with no other signs of metastasis in the presence of neurological symptoms should arouse suspicion.

Surgical resection when appropriate (31) plus WBRT has been previously used in patients with brain metastasis from gynecological malignancies. Certain studies have reported improved outcomes with multimodality treatments that include surgical resection $(8,14)$. However, the majority of series have used WBRT to treat these patients. In fact, the Hellinic Oncology Group reported poor outcomes primarily with the use of WBRT or supportive care (32).

Prior studies have reported the use of SRS in patients with brain metastasis from gynecological malignancies. (27,33-35). Improved outcomes after SRS compared with WBRT $(25,33,35)$ could reflect selection bias. Patients with isolated or 
limited CNS disease, controlled systemic disease and reasonable performance status appear to do well overall $(19,24)$, and are those who could potentially benefit from WBRT-sparing approaches such as SRS. In the present study, it was shown that patients with a reasonable performance status and controlled systemic disease can achieve excellent local control rates and achieve long overall survival times with SRS treatment alone. This is particularly true due to the high efficacy of SRS for isolated brain relapses, with WBRT reserved for widespread and leptomeningeal metastases.

In conclusion, brain metastasis from gynecological malignancies is rare. Systemic therapy is effective in patients with metastatic cancer of the female genital tract, who can subsequently survive for a long period of time. In this setting, when these patients present with limited brain metastasis, surgery (when appropriate) and/or SRS is effective in controlling the brain disease.

\section{References}

1. Siegel R, Naishadham D and Jemal A: Cancer statistics, 2013. CA Cancer J Clin 63: 11-30, 2013.

2. Jemal A, Bray F, Center MM, Ferlay J, Ward E and Forman D: Global cancer statistics. CA Cancer J Clin 61: 69-90, 2011.

3. Jemal A, Center MM, DeSantis C and Ward EM: Global patterns of cancer incidence and mortality rates and trends. Cancer Epidemiol Biomarkers Prev 19: 1893-1907, 2010.

4. Aalders JG, Abeler V and Kolstad P: Recurrent adenocarcinoma of the endometrium: A clinical and histopathological study of 379 patients. Gynecol Oncol 17: 85-103, 1984.

5. Chura JC, Marushin R, Boyd A, Ghebre R, Geller MA and Argenta PA: Multimodal therapy improves survival in patients with CNS metastasis from uterine cancer: A retrospective analysis and literature review. Gynecol Oncol 107: 79-85, 2007.

6. Ikeda S, Yamada T, Katsumata N, Hida K, Tanemura K, Tsunematu R, Ohmi K, Sonoda T, Ikeda H and Nomura K: Cerebral metastasis in patients with uterine cervical cancer. Jpn J Clin Oncol 28: 27-29, 1998.

7. Cordeiro JG, Prevedello DM, da Silva Ditzel LF, Pereira CU and Araújo JC: Cerebral metastasis of cervical uterine cancer: Report of three cases. Arq Neuropsiquiatr 64: 300-302, 2006.

8. Cormio G, Lissoni A, Losa G, Zanetta G, Pellegrino A and Mangioni C: Brain metastases from endometrial carcinoma. Gynecol Oncol 61: 40-43, 1996.

9. Root K and Armaghany T: Solitary brain metastasis in a patient with ovarian cancer with BRCA2 mutation. J Clin Oncol 30: e239-e240, 2012.

10. Kastritis E, Efstathiou E, Gika D, Bozas G, Koutsoukou V, Papadimitriou C, Pissakas G, Dimopoulos MA and Bamias A: Brain metastases as isolated site of relapse in patients with epithelial ovarian cancer previously treated with platinum and paclitaxel-based chemotherapy. Int J Gynecol Cancer 16: 994-999, 2006.

11. Leath CA III and Straughn JM Jr: Chemotherapy for advanced and recurrent cervical carcinoma: Results from cooperative group trials Gynecol Oncol 129: 251-257, 2013.

12. Vale CL, Tierney J, Bull SJ and Symonds PR: Chemotherapy for advanced, recurrent or metastatic endometrial carcinoma. Cochrane Database Syst Rev 8: CD003915, 2012.

13. Foley OW, Rauh-Hain JA and del Carmen MG: Recurrent epithelial ovarian cancer: An update on treatment. Oncology 27:288-294, 2013.

14. Rodriguez GC, Soper JT, Berchuck A, Oleson J, Dodge R, Montana $\mathrm{G}$ and Clarke-Pearson DL: Improved palliation of cerebral metastases in epithelial ovarian cancer using a combined modality approach including radiation therapy, chemotherapy, and surgery. $\mathrm{J}$ Clin Oncol 10: 1553-1560, 1992.

15. Bruzzone M, Campora E, Chiara S, Giudici S, Merlini L, Simoni C, Mammoliti S, Rubagotti A and Rosso R: Cerebral metastases secondary to ovarian cancer: Still an unusual event. Gynecol Oncol 49: 37-40, 1993.
16. Stein M, Steiner M, Klein B, Beck D, Atad J, Kuten A, Robinson E and Goldsher D: Involvement of the central nervous system by ovarian carcinoma. Cancer 58: 2066-2069, 1986.

17. Hardy JR and Harvey VJ: Cerebral metastases in patients with ovarian cancer treated with chemotherapy. Gynecol Oncol 33: 296-300, 1989

18. Chen YL, Cheng WF, Hsieh CY and Chen CA: Brain metastasis as a late manifestation of ovarian carcinoma. Eur J Cancer Care (Engl) 20: 44-49, 2011.

19. McMeekin DS, Kamelle SA, Vasilev SA, Tillmanns TD, Gould NS, Scribner DR, Gold MA, Guruswamy S and Mannel RS: Ovarian cancer metastatic to the brain: What is the optimal management? J Surg Oncol 78: 194-200, 2001.

20. Hu XQ, Imitola J, Kim RY, Mahta A and Kesari S: Brain metastasis from ovarian cancer: Case report and review of the literature. Med Oncol 29: 1250-1252, 2012.

21. Chang EL, Wefel JS, Hess KR, Allen PK, Lang FF, Kornguth DG, Arbuckle RB, Swint JM, Shiu AS, Maor MH and Meyers CA: Neurocognition in patients with brain metastases treated with radiosurgery or radiosurgery plus whole-brain irradiation: A randomised controlled trial. Lancet Oncol 10: 1037-1044, 2009.

22. Patchell RA, Tibbs PA, Regine WF, Dempsey RJ, Mohiuddin M, Kryscio RJ, Markesbery WR, Foon KA and Young B: Postoperative radiotherapy in the treatment of single metastases to the brain: A randomized trial. JAMA 280: 1485-1489, 1998.

23. Aoyama H, Shirato H, Tago M, Nakagawa K, Toyoda T, Hatano K, Kenjyo M, Oya N, Hirota S, Shioura H, et al: Stereotactic radiosurgery plus whole-brain radiation therapy vs stereotactic radiosurgery alone for treatment of brain metastases: A randomized controlled trial. JAMA 295: 2483-2491, 2006.

24. Anupol N, Ghamande S, Odunsi K, Driscoll D and Lele S: Evaluation of prognostic factors and treatment modalities in ovarian cancer patients with brain metastases. Gynecol Oncol 85: 487-492, 2002.

25. Shiohara S, Ohara M, Itoh K, Shiozawa T and Konishi I: Successful treatment with stereotactic radiosurgery for brain metastases of endometrial carcinoma: A case report and review of the literature. Int J Gynecol Cancer 13: 71-76, 2003.

26. Elliott KS, Borowsky ME, Lee YC, Rao C and Abulafia O: Prolonged survival in recurrent endometrial carcinoma to the brain. Gynecol Oncol 95: 247-251, 2004.

27. Chung SB, Jo KI, Seol HJ, Nam DH and Lee JI: Radiosurgery to palliate symptoms in brain metastases from uterine cervix cancer. Acta Neurochir (Wien) 155: 399-405, 2013.

28. Agrawal A, Kumar A, Sinha AK, Kumar M, Pandey SR and Khaniya S: Intracranial metastases from carcinoma of the cervix. Singapore Med J 48: e154-e156, 2007.

29. Park SH, Ro DY, Park BJ, Kim YW, Kim TE, Jung JK, Lee JW, Kim JY and Han CW: Brain metastasis from uterine cervical cancer. J Obstet Gynaecol Res 36: 701-704, 2010.

30. Cooper KG, Kitchener HC and Parkin DE: Cerebral metastases from epithelial ovarian carcinoma treated with carboplatin. Gynecol Oncol 55: 318-323, 1994.

31. Pothuri B, Chi DS, Reid T, Aghajanian C, Venkatraman E, Alektiar K, Bilsky M and Barakat RR: Craniotomy for central nervous system metastases in epithelial ovarian carcinoma. Gynecol Oncol 87: 133-137, 2002.

32. Pectasides D, Aravantinos G, Fountzilas G, Kalofonos C, Efstathiou E, Karina M, Pavlidis N, Farmakis D, Economopoulos T and Dimopoulos MA: Brain metastases from epithelial ovarian cancer. The Hellenic Cooperative Oncology Group (HeCOG) experience and review of the literature. Anticancer Res 25: 3553-3558, 2005.

33. Lee YK, Park NH, Kim JW, Song YS, Kang SB and Lee HP: Gamma-knife radiosurgery as an optimal treatment modality for brain metastases from epithelial ovarian cancer. Gynecol Oncol 108: 505-509, 2008

34. Monaco E III, Kondziolka D, Mongia S, Niranjan A, Flickinger JC and Lunsford LD: Management of brain metastases from ovarian and endometrial carcinoma with stereotactic radiosurgery. Cancer 113: 2610-2614, 2008.

35. Niu X, Rajanbabu A, Delisle M, Peng F, Vijaykumar DK, Pavithran K, Feng Y, Lau S, Gotlieb WH and Press JZ: Brain metastases in women with epithelial ovarian cancer: Multimodal treatment including surgery or gamma-knife radiation is associated with prolonged survival. J Obstet Gynaecol Can 35: 816-822, 2013. 